\title{
O CONSUMO DE CACHAÇA E SEUS SENTIDOS: UMA ANÁLISE DO COMPORTAMENTO DO CONSUMIDOR À LUZ DA TEORIA DO SENSEMAKING
}

\section{CACHAÇA CONSUMPTION AND ITS MEANINGS: AN ANALYSIS OF CONSUMER BEHAVIOR IN THE LIGHT OF THE SENSEMAKING THEORY}

\author{
ELISABETH THAIANE TERCINO DE ARAÚJO \\ Universidade Federal de Lavras (UFLA) \\ Mestre em Administração - Universidade Federal de Lavras (PPGA/UFLA) \\ Orcid: https://orcid.org/0000-0001-6402-726X / E-mail: elisabethtercino@yahoo.com.br \\ Praça Leonardo Venerando Pereira, 304, apto 305, Centro, Lavras-MG, CEP: 37200-130

\section{JOSÉ KENNEDY LOPES SILVA} \\ Universidade Federal de Rondônia (UNIR) / Universidade Federal de Lavras (UFLA) \\ Professor do Departamento de Administração campus de Vilhena - UNIR \\ Doutorando do PPG em Administração da Universidade Federal de Lavras (PPGA/UFLA) \\ Orcid: http://orcid.org/0000-0002-8669-6429 / E-mail: kennedysilv@gmail.com \\ FLÁVIA CAROLINI PEREIRA DOS SANTOS \\ Universidade Federal de Lavras (UFLA) \\ Mestre em Administração - Universidade Federal de Lavras (PPGA/UFLA) \\ Orcid: https://orcid.org/0000-0003-4620-8010 / E-mail: flaviacarolini2013@gmail.com
}

\section{ANA CRISTINA FERREIRA}

Universidade Federal de Lavras (UFLA)

Doutoranda do PPG em Administração da Universidade Federal de Lavras

Orcid: https://orcid.org/0000-0002-4726-1086 / E-mail: ana-cristina18@hotmail.com

Submissão: 18/04/2020. Revisão: 25/10/2020. Aceite:29/12/2020. Publicação: 01/03/2021.

DOI: http://dx.doi.org/10.22277/rgo.v14i1.5392

\section{RESUMO}

A produção e o consumo de cachaça são importantes para o Brasil, tanto na perspectiva econômica e cultural quanto social. Desse modo, justifica-se a necessidade de se pesquisar sobre o consumo desse produto cultural brasileiro. Esta pesquisa aproxima as teorias do Sensemaking e do Comportamento do Consumidor e busca compreender os sentidos atribuídos à cachaça por parte dos consumidores da bebida. Ancorada na abordagem qualitativa, os dados coletados em um formulário virtual foram analisados por meio da análise de conteúdo, com base em categorias de análise da teoria do Sensemaking e do consumo do ponto de vista cultural. Os resultados apontaram que os degustadores bebem a cachaça, veem-na como uma oportunidade de socializar e afirmam que começaram a beber em ambientes familiares, sugerindo que esse hábito seja uma tradição familiar. Quanto ao comportamento, os consumidores são exigentes no que diz respeito ao sabor, à qualidade e ao preço da cachaça e demonstram conservadorismo em relação ao consumo por homens e mulheres. Este trabalho contribui para a produção de artigos sobre os consumidores de cachaça, produto que ainda enfrenta preconceito, além disso, é importante para as organizações produtoras de cachaças, já que ouvir quem de fato produz o sentido acerca do produto em questão pode dar um direcionamento em relação ao que os consumidores querem beber para que se tornem fiéis, promovendo de maneira responsável o consumo desta bebida.

Palavras-chave: Sensemaking. Comportamento do consumidor. Consumo Cultural. Cachaça. 
Consumo de cachaça e seus sentidos:

uma análise do comportamento do consumidor à luz da teoria do Sensemaking

\begin{abstract}
The production and consumption of cachaça are important for Brazil from an economic, cultural, and social point of view. Therefore, the need to research the consumption of this Brazilian cultural product is justified. This research combines the theories of Sensemaking and Consumer Behavior and aims to understand the meanings attributed to cachaça by drinkers. Based on a qualitative approach, the data collected in an online questionnaire were analyzed through the content analysis technic, based on the categories of analysis of the Sensemaking theory and of the consumption from a cultural point of view. The results showed that consumers drink cachaça, perceive it as an opportunity to socialize and state that they started drinking in a family environment, suggesting that this habit is a family tradition. Regarding the behavior, consumers are demanding in terms of taste, quality and price of the cachaça and demonstrate conservatism in relation to the consumption by men and women. This work contributes to the production of articles about consumers of cachaça, a product that still faces prejudices, in addition is important for organizations that produce cachaças, as listening to those who actually produce the meaning of the product in question can provide a guidance in relation to what consumers want to drink so that they become loyal, promoting a responsible consumption of this drink.
\end{abstract}

Keywords: Sensemaking. Consumer behavior. Cultural Consumption. Cachaça.

\title{
1 INTRODUÇÃO
}

Conforme levantamento realizado até o final de dezembro de 2018 , os produtores de cachaça totalizam 951 estabelecimentos registrados. Desse montante, a liderança fica com o Estado de Minas Gerais, e, na sequência, aparecem os Estados de São Paulo, Espírito Santo e Rio de Janeiro, o que evidencia a concentração da produção de cachaça na região Sudeste, representando mais de $70 \%$ da produção nacional, ou seja, 671 estabelecimentos (BRASIL, 2019). O setor tem sido responsável por um significativo e promissor faturamento, bem como pela contratação de parte considerável da mão de obra brasileira (CHALITA, 2008; ANDRADE; ANDRADE, 2015). Portanto, compreende-se a relevância desta principalmente do ponto de vista nacional, uma vez que a bebida e a sua cadeia de produção e consumo é objeto de pesquisa científica, inovação tecnológica, além de fazer parte de programas de exportação do Governo Federal. Nesse sentido, a cachaça trata-se de um patrimônio cultural do país, responsável por significativa geração de renda e fortalecimento da economia (BORGES; TAKEMOTO, 2019).

Teixeira e Shigaki (2018) propõem que a pesquisa e os estudos sobre consumo devem revisar suas origens, principalmente as que tratam do pensamento mercadológico. Essas discussões apresentadas nos estudos dos autores são exemplos da consolidação pesquisas de fenômenos de base simbólica e social que foi parte de um grande projeto iniciado por Russel Belk em 1985 chamado de Odisséia. Tal projeto propiciou o surgimento de novos métodos, ferramentas de coleta de dados e também contribuiu com a forma de analisá-los (CAMPOS; NASCIMENTO; PINHO, 2018). Desse modo, a busca da compreensão do sentidos e do comportamento do consumidor é necessário para as organizações de qualquer tamanho e segmento, uma vez que alinhar essas possibilidades permite aos atores organizacionais aumentar a probabilidade de atender melhor os seus clientes. Tratando-se especificamente do segmento de cachaça, destaca-se que o que não é diferente, tendo em vista que o produto este que destaca-se historicamente na cultura brasileira, enquanto representante da 
Elisabeth Thaiane Tercino de Araújo, José Kennedy Lopes Silva, Flávia Carolini Pereira dos Santos e Ana Cristina Ferreira

brasilidade, identidade e culinária do país (ANDRADE; ANDRADE, 2015; BRAGA; KIYOTANI, 2015).

No sentido dessa discussão, esse artigo ancorado na teoria do sensemaking e do comportamento do consumidor se pauta no seguinte problema: Como se produz os sentidos e o comportamento dos consumidores degustadores de cachaça artesanal de alambique? Para tanto, o objetivo é analisar o comportamento dos apreciadores e compreender os sentidos por eles atribuídos ao consumo de cachaça artesanal de alambique. A relevância do estudo se dá por ter como público os apreciadores do destilado, adeptos a um consumo onde se valoriza a história, a cultura e a qualidade da bebida, além de ser um tema promissor em pesquisas sobre o comportamento de consumo, especialmente em relação a aspectos simbólicos, sociais, culturais e o seu significado enquanto produto genuinamente nacional (PAIVA et al., 2017; BRAGA; KIYOTANI, 2015; ANDRADE, ANDRADE, 2015; SANDRE, 2004).

A pesquisa é construída da seguinte forma: na primeira parte do referencial teórico é condensada a conceituação da teoria do sensemaking e entendimento do que significa produzir sentidos para os indivíduos. Para isso, apresenta-se as sete propriedades que compõem essa teoria (WEICK, 1995), são elas: (I) Fundamentado na construção da identidade; (II) Caráter retrospectivo; (III) Criado em ambientes dinâmicos; (IV) Contato social; (V) Eventos contínuos; (VI) Sugestões e Palpites; e (VII) Guiado pela plausibilidade ao invés da precisão. Após isso, são apresentadas para reflexão as confluências teóricas de pesquisadores da área do marketing sobre o consumo do ponto de vista cultural. A última parte do arcabouço teórico é exposta com a apresentação do produto aqui analisado, a cachaça. A segunda parte dessa pesquisa é a utilização de procedimentos metodológicos que permitirão a análise de formulários a partir da apreciação desse tipo de bebida alcoólica por seus consumidores. $E$, por fim, a última parte da pesquisa expõe os resultados das análises e as considerações finais.

\section{REFERENCIAL TEÓRICO-EMPÍRICO}

\subsection{SENSEMAKING}

O sensemaking tem sido bastante utilizado e, por consequência, tem influenciado as pesquisas em estudos organizacionais (HULTIM; MÄHRING, 2017). Embora não exista um consenso acerca desse conceito, essa perspectiva e/ou abordagem está sendo associada fortemente à pesquisa interpretativa, construcionista social, processual e/ou fenomenológica. Jeong e Brower (2008) reforçam que, por esse motivo, a literatura de sensemaking está longe de ser homogênea. Todavia, sob essa lente teórica, surge uma considerável base analítica para se compreender diferentes fenômenos organizacionais (CORREA et al., 2014).

O sensemaking é a construção dos sentidos criado pelos indivíduos, uma vez que estes são atores envolvidos de maneira prática nessas situações (JEONG; BROWER, 2008). Consequentemente, construir sentidos é um processo no qual os atores individuais reconhecem e resolvem seus problemas com situações que encontram e, ao fazê-lo, dispersam essas situações com as sementes de outros problemas. Para Munck (2015), o sensemaking se refere a um processo de construção social em que os atores se envolvem na interpretação e explicação de aspectos sobre o seu ambiente, em um esforço para criar ordem e sentido retrospectivo ao que ocorre.

Weick (1995), autor seminal da teoria, tem o entendimento das organizações como organizing, ressaltando a sua natureza processual (DUARTE; ALCADIPANI, 2016), isto é, o termo organizing evidencia que o processo organizacional se trata de ação contínua, em constante movimento (MONTENEGRO; CASALI, 2008; WEICK, 1995). Nessa perspectiva, 
Consumo de cachaça e seus sentidos:

uma análise do comportamento do consumidor à luz da teoria do Sensemaking

Cunliffe e Coupland (2016) compreendem o sensemaking como um processo representacional, cognitivo, informacional e/ou comunicativo, contrário à ideia de uma atividade retrospectiva e linear. Além disso, amparam-se sobre a teoria da narrativa para propor que sensemaking é um processo temporal de tornar a vida e a pessoas sensíveis através de performances narrativas incorporadas.

Como processo interpretativo, julga-se a experiência, ações e senso de identidade em relação a outros específicos e generalizados (CUNLIFFE; COUPLAND, 2016). Portanto, a construção de sentido se constitui como uma realização contínua através da qual as pessoas criam suas situações e ações e tentam torná-las racionalmente responsáveis perante si mesmas e aos outros (ALLARD-POESI, 2005; WEICK, 2012).

Diante dessa explanação inicial sobre o sensemaking, é importante ressaltar as sete propriedades que o compõem (WEICK, 1995), tendo em vista que são de suma importância para a análise a ser realizada neste trabalho. Destacam-se:

(I) Fundamentado na construção da identidade: um sensemaker dificilmente atua sozinho, dado que a identidade do indivíduo é fruto da interação com outrem, o que corrobora a concepção de uma identidade coletiva;

(II) Caráter retrospectivo: a concepção de um sentido se dá em um processo cuja atenção está em um momento posterior ao acontecimento. Desse modo, o olhar está direcionado para um momento retrospectivo, o que implica na constante movimentação dos sentidos a cada memoração de um determinado fato;

(III) Criado em ambientes dinâmicos - Weick considera que os ambientes são por natureza dinâmicos, ativos, mutáveis e que sofrem a influência direta das pessoas, as quais compõem esses espaços e são as principais causas desse movimento constante;

(IV) Contato social - o sensemaking nunca é fruto de um só indivíduo, pois se considera que a ação de um implica diretamente nos outros. Até mesmo a inação possui impacto direto aos demais;

(V) Eventos contínuos - o sensemaking não tem um ponto exato de início, tendo em vista que os sentidos estão sempre presentes em fluxos contínuos nos quais os indivíduos são protagonistas;

(VI) Sugestões ou palpites - são consideradas "sementes" a partir das quais as pessoas desenvolvem um sentido mais amplo sobre o que pode estar ocorrendo;

(VII) Guiado pela plausibilidade ao invés da precisão, - o sensemaking não é sobre verdade e certeza, mas sobre a reformulação contínua de uma história emergente para que ela se torne mais compreensiva (CZARNIAWSKA, 2005; WEICK, 1995).

Brown, Colville e Pye (2015) evidenciam que existem alguns aspectos que são passíveis de análise, tendo em vista a discussão sob diferentes perspectivas acerca da construção de sentido e suas aplicações. Cada vez mais, há evidências de que os acadêmicos estão procurando revitalizar os discursos centrados no sensemaking, buscando novas fontes de inspiração e novas direções para a teorização (HOLT; CORNELISSEN, 2014). Desse modo, a construção de sentido se torna central, uma vez que se constitui como o principal local onde os significados se materializam, informam e restringem a identidade e a ação (WEICK; SUTCLIFFE; OBSTFELD, 2005).

A partir da discussão de sensemaking, faz-se necessário apresentar, no contexto deste 
Elisabeth Thaiane Tercino de Araújo, José Kennedy Lopes Silva, Flávia Carolini Pereira dos Santos e Ana Cristina Ferreira

trabalho, a perspectiva teórica sobre consumo, como uma prática permeada por significados culturalmente estabelecidos.

\subsection{CONSUMO NA PERSPECTIVA CULTURAL}

O consumo é um tema discutido sob diferentes perspectivas, podendo ser considerado, em determinado prisma, como inerente à condição humana e indispensável à sua sobrevivência (PINTO; BATINGA, 2016). Sendo assim, Bauman (2008) o situa entre as necessidades mais remotas da vida humana. Costa e Teodósio (2011), por sua vez, consideram que o ato do consumo é pertencente à vida humana contemporânea, pois baliza as relações sociais e faz parte da dinâmica da economia. O consumo possui caráter multidimensional e amplo, abarcando outras áreas de estudo como a sociologia, a antropologia, a história, a administração, a psicologia, a filosofia, dentre outras.

Destaca-se, contudo, que a atenção e enfoque dados ao consumo se justificam pelo fato de se tratar de uma das atividades humanas que extrapolam o sentido da simples troca, revestindo-se de simbolismo e se constituindo, portanto, como uma das tarefas mais importantes das sociedades modernas (BARBOSA; CAMPBELL, 2006). Para os autores, o consumo se tornou um campo complexo, que envolve várias atividades, atores, e um conjunto de bens e serviços que não se restringem aos providos sob a forma de mercadoria. Assim:

Consumo é ao mesmo tempo um processo social que diz respeito a múltiplas formas de provisão de bens e serviços e a diferentes formas de acesso a esses mesmos bens e serviços; um mecanismo social percebido pelas ciências sociais como produtor de sentido e de identidades, independentemente da aquisição de um bem; uma estratégia utilizada no cotidiano pelos mais diferentes grupos sociais para definir diversas situações em termos de direitos, estilo de vida e identidades; e uma categoria central na definição da sociedade contemporânea (BARBOSA; CAMPBELL, 2006, p. 26).

Barros (2006) e Pinto e Batinga (2016) também ajudam a jogar luz sobre o conceito de consumo ao defenderem que este pode ser percebido como uma combinação de elementos tangíveis e intangíveis, em que a individualidade de cada ator está inserida em um conjunto interligado de relações sociais e culturais. Dessa maneira, não há como negar que, na construção social da atualidade, as identidades dos cidadãos se configuram também pelo consumo, de modo que o status, muitas vezes, pode ser medido pelo que se consome (COSTA; TEODÓSIO, 2011).

Embora sejam múltiplas as lentes de análise voltadas para o consumo, neste trabalho, considera-se que todo consumo envolve um significado (PINTO; BATINGA, 2016). Isso equivale dizer que o consumo representa o que os indivíduos e os grupos são capazes de interpretar, transformar, resistir e modificar padrões culturais e significados previamente estabelecidos (BERTUOL et al., 2017). A importância de se considerar os aspectos culturais possibilita ao indivíduo assimilar os fenômenos e aprender sobre eles, a partir de um novo ponto de vista, além de ser uma diretriz de ações sociais e atividades produtivas capazes de caracterizar os comportamentos e os objetos que derivam de tais feitos (NATT et al., 2017). Logo, o consumo se configura como uma prática permeada por diversas questões que podem expressar, inclusive, a identidade, os valores, os gostos, os costumes e as tradições dos indivíduos. Desse modo, a cultura constrói e atribui significado ao mundo (MCCRACKEN, 2007).

O consumo começou a ser visto a partir de uma "visão experiencial" que envolve diversos aspectos, bem como um fluxo constante de fantasias, sentimentos e diversão. Essa perspectiva de caráter experiencial é fenomenológica em espírito e considera a incorporação

RGO - Revista Gestão Organizacional, Chapecó, v. 14, n. 2, p. 46-68, maio/ago. 2021. 
Consumo de cachaça e seus sentidos:

uma análise do comportamento do consumidor à luz da teoria do Sensemaking

como um estado essencialmente subjetivo de consciência cujos significados simbólicos, respostas hedônicas e critérios estéticos fazem parte (HOLBROOK; HIRSCHMAN, 1982). Dessa forma, considera-se a lógica do consumo como a manipulação dos signos (BAUDRILLARD, 1995).

Seguindo essa mesma corrente, Pinto e Batinga (2016) consideram que os indivíduos interpretam sensações, experiências e situações, e, simultaneamente, dão sentido a vários objetos, ações e recursos sejam eles relacionados ou não com essas experiências. Os significados envolvidos são partilhados, uma vez que as formas de consumo são articuladas conforme as formas de vida significativas e específicas (PINTO; BATINGA, 2016). Nessa lógica, a única realidade objetiva do consumo é a ideia cuja reflexividade e discurso intelectual ganha força no senso comum (BAUDRILLARD, 1995).

Rocha e Barros (2006) afirmam que o consumo é um sistema de significação, ou seja, é como um código e, por meio dele, são traduzidas boa parte das relações sociais. Para Pinto e Lara (2011), a própria circulação, compra, venda, apropriação de bens e de objetos/signos diferenciados constituem uma linguagem comum e um código, por meio dos quais toda a sociedade se comunica. Consequentemente, os consumidores utilizam o significado dos bens de consumo para manifestar categorias e princípios culturais, promover ideias, criar e manter estilos de vida, (re)construir noções de si e sobreviver a mudanças sociais (McCRACKEN, 2007).

Nessa perspectiva, McCracken (2003) ressalta que os produtos são depositários de significados culturais que podem estar evidentes ou escondidos para o consumidor, uma vez que assumem um significado que ultrapassa seu valor de mercado e seu caráter utilitário (McCRACKEN, 2007; BERTUOL et al., 2017). O consumir se traduz como um ato simbólico, carregando consigo diversos significados, influenciados, sobretudo, pelos valores culturais e individuais que norteiam a ação de cada um (TONI; LARENTIS; MATTIA, 2012).

Uma limitação das abordagens mais recentes para o estudo do significado cultural dos bens de consumo é que tais perspectivas não consideram que o significado está constantemente em trânsito (McCRACKEN, 2007). Em síntese, é possível afirmar que o significado cultural é absorvido pelo mundo cultural e transferido para os bens de consumo e que, de modo prático, o significado cultural perpassa pelo mundo cultural constituído, no bem de consumo e no consumidor individual (MCCRACKEN, 2007). O significado cultural trata-se das ações cotidianas e rotineiras que compreendem os fenômenos e os sentidos individuais e transcorrem pelas crenças e pela cultura.

Em suma, considera-se que o significado cultural dos bens de consumo está presente em três lugares: no mundo culturalmente constituído, no bem de consumo e no consumidor individual, movendo-se numa trajetória que perpassa do mundo para o bem de consumo e do bem de consumo para o indivíduo (MCCRACKEN, 1986; 2007). Portanto, a transferência de significados se torna o lócus do significado cultural. A jornada do significado por meio do mundo social finaliza no momento em que ele finalmente se assenta no consumidor. Bertuol et al. (2017) destacam que, embora bastante criticado, o modelo de McCracken (1986) implicou um marco na teoria sobre significados dos bens de consumo, uma vez que apresenta e analisa um processo de transferência e movimento dos significados, o qual era negligenciado pela academia até aquele o momento. A partir dessa perspectiva, os estudos passaram a analisar, sob a ótica dos consumidores, o significado dos bens de consumo.

Dessa maneira, em relação a essas pesquisas, McCracken (2012) destaca a pertinência de investigações voltadas para grupos específicos, entre os quais a abordagem que considera que a transferência de significados do mundo culturalmente constituído se dá de uma maneira diferente da individual. Então, o estudo nas confrarias - como espaços organizativos 
Elisabeth Thaiane Tercino de Araújo, José Kennedy Lopes Silva, Flávia Carolini Pereira dos Santos e Ana Cristina Ferreira

específicos - a respeito dos sentidos atribuídos ao consumo, sob a ótica dos membros, caminha exatamente na direção a qual McCracken (2012) destacou a importância.

Apresentado o embasamento teórico acerca do consumo, é exposto, em seguida, o campo empírico deste artigo que se trata da Cachaça, produto este que tem uma história relevante para o País e, ao longo do tempo, vem sendo ressignificado pelos seus consumidores e pelo Mercado.

\subsection{A CACHAÇA ARTESANAL DE ALAMBIQUE}

Historicamente, a produção da cachaça está presente desde o período Colonial, cuja matéria prima assumia, nesse período, um importante papel na economia portuguesa. Sandre (2004) explica que o caldo obtido através do processo de moagem da cana de açúcar era levado para a casa das caldeiras e fervido em grandes tachos de cobre ou de ferro batido até engrossar. O melaço obtido era transferido para outros recipientes de madeira e carregado para a casa de purgar. Nesse local, as formas de barro com o melaço permaneciam por vários dias, até a cristalização do açúcar. O complexo que compreendia a lavoura, o engenho e a moenda da cana- de-açúcar, formava uma unidade de produção autossuficiente, responsável por sua própria subsistência (SANDRE, 2004).

Uma das versões para a origem da bebida revela que algumas vezes os escravizados deixavam o moinho do engenho com os restos do trabalho do dia, ou seja, o caldo da cana de açúcar (CARDOSO et al., 2005). Esse caldo azedava e resultava, a partir da fermentação submetida, em uma mistura contendo álcool em sua composição (OLIVEIRA, 2000). O consumo da bebida pelos escravizados resultava em um comportamento diferente, na produtividade aumentada do engenho e em um clima de descontração (OLIVEIRA, 2000; CARDOSO et al., 2005). Assim, Tavares, Dantas e Nóbrega (2015) afirmam que o surgimento da cachaça ocorreu por coincidência, pois a experimentação da bebida pelos escravizados foi decorrente da observação do comportamento dos animais. Contudo, essa é apenas uma das diversas versões acerca do "descobrimento" da cachaça.

A cana-de-açúcar, na época colonial, possuía maior destaque econômico, tendo em vista a produção de açúcar, porém, é necessário considerar que tão logo se descobriu a maneira de destilação do caldo da cana, a expansão dessa cultura também carregou mais um objetivo para o seu cultivo, o de produzir cachaça (OLIVEIRA, 2000). Cascudo (2014) evidencia que a aguardente elaborada no Brasil atendia a diversos fregueses, especialmente àqueles que possuíam reduzida pecúnia. No entanto, não era apenas e unicamente a bebida vulgar de escravizados e navegantes, uma vez que esta passa a estar presente inclusive na mesa dos senhores de engenho.

A partir da presença da cachaça na história do Brasil, é possível entender o reconhecimento dessa bebida como símbolo do patrimônio cultural brasileiro (TAVARES; DANTAS; NÓBREGA, 2015). Embora durante muito tempo a cachaça tenha sido marcada pelo estigma de um produto marginalizado, atualmente, a bebida é conhecida e reconhecida, como um produto de alto valor econômico e inserção internacional altamente promissora (OLIVEIRA et al., 2012). Então, observa-se que a Cachaça exerce um importante papel econômico, social e cultural no Brasil, uma vez que se trata de uma bebida oficialmente brasileira cujos diversos métodos e normas regulamentam a sua produção (BRAGA; KIYOTANI, 2015).

Predominam duas formas distintas de produção da bebida, sendo elas: a cachaça industrializada e a cachaça de Alambique. Coutinho (2003) as diferencia de uma maneira bem simples: no segmento industrial, o processo produtivo é realizado em grandes empresas, com 
Consumo de cachaça e seus sentidos:

uma análise do comportamento do consumidor à luz da teoria do Sensemaking

aparato tecnológico e sob controle técnico. No entanto, no segmento artesanal, a bebida é processada em empresas tipicamente familiares, com baixa escala de produção; os procedimentos produtivos têm vínculos com as tradições do território e, geralmente, reproduzem práticas ultrapassadas, muitas vezes comprometendo a qualidade da aguardente. Oliveira (2010) ressalta que a legislação não estabeleceu uma distinção entre os produtos finais das destilarias industriais e dos alambiques artesanais, contudo, na prática, é possível notar muitas diferenças entre ambos, inclusive nas etapas de produção.

Morais et. al. (2020) discorrem sobre o trabalho realizado entre os produtores de cachaça e a Associação Nacional de Produtores e Integrantes da Cadeia Produtiva da Cachaça (ANPAQ) para a interrupção e/ou diminuição da informalidade nas práticas de produção de cachaça. Para os autores, o trabalho institucional realizado pelos produtores de cachaça e pela ANPAQ, apesar de ainda não ter sido concluído, oferece avanços em relação à imagem do produto entre os consumidores, o que, de certo modo, influencia a produção de sentido dos antigos e novos consumidores de cachaça.

Silva (2009) comenta que a diferenciação do produto artesanalmente produzido acontece em função de diversas características, especialmente em relação à qualidade, à marca (griffe), ao padrão de acabamento, à existência ou não de assistência técnica, dentre outros. O fato é que, no universo das mais variadas modalidades de cachaça, existem características passíveis de agradar a todos os paladares, algumas mais suaves e de coloração mais harmônicas, outras com "maior personalidade", dito sobre aquelas com aromas e sabores mais profundos e expressivos. Portanto, trata-se de uma bebida com uma diversidade que contempla as exigências dos vários estilos e culturas dos consumidores em potencial e dos amantes da caninha brasileira (BRAGA; KIYOTANI, 2015). Acredita-se que o consumidor de cachaça seja mais refinado e exigente, que o distingue da parcela de consumidores tradicionais de cachaças industrializadas, reverenciando a importância de seu paladar (OLIVEIRA et al., 2012).

Apresentada a discussão teórica sobre Sensemaking, Consumo Cultural e história da cachaça no cenário nacional, segue a explicação sobre os procedimentos metodológicos utilizados na construção deste artigo.

\section{PROCEDIMENTOS METODOLÓGICOS}

A abordagem metodológica para a construção deste trabalho é baseada na perspectiva qualitativa, especialmente, por se tratar de uma metodologia plural em suas aplicações epistemológicas e ontológicas, fundamentadas no interacionismo simbólico e interpretativismo (LOURENÇO; FERREIRA; ROSA, 2014). Considera-se que a aplicação da pesquisa qualitativa enriquece os diversos campos de conhecimento, inclusive o do Marketing, tendo em vista que os desafios propostos por esses tipos de pesquisas é o que permite o avanço das teorias e do conhecimento produzido pelos e para os pesquisadores da área. Entretanto, diversas críticas são feitas em relação à dificuldade de generalização dos dados nesse tipo de pesquisa, conforme ressalta Campomar (2006), porém utilizou-se essa abordagem com o intuito de identificar os significados e compreender os sentidos atribuídos ao consumo de consumo de cachaça por seus apreciadores.

Em relação aos objetivos, é possível classificar a presente pesquisa como descritiva, tendo em vista que, por meio da coleta de dados, pretendeu-se observar e descrever as características da temática por meio de registro e análise dos fatos e/ou fenômenos que representam a própria realidade (TEIXEIRA; NASCIMENTO; ANTONIALLI, 2012). Assim, diante 
Elisabeth Thaiane Tercino de Araújo, José Kennedy Lopes Silva, Flávia Carolini Pereira dos Santos e Ana Cristina Ferreira

da natureza e do tipo de pesquisa deste trabalho, como coleta de dados, utilizou-se unicamente formulários com questões dissertativas, disponíveis em meio online para que os respondentes pudessem se sentir à vontade para responder de acordo com suas concepções.

O roteiro do formulário foi composto pelas seguintes partes: Parte I - caracterização do participante: nome, gênero, idade, renda familiar mensal, escolaridade, profissão, estado civil, tempo de consumo de cachaça, frequência média desse consumo semanalmente e preço médio pago por uma garrafa de cachaça; Parte II - Caracterização do consumo dos respondentes; participação em cursos, eventos, festivais; o que prioriza ao escolher uma cachaça artesanal; características desses apreciadores; participação do processo produtivo; quais as marcas preferidas; o que se prioriza ao escolher uma cachaça; associação da bebida a categorias como sexo, classe social e idade; visão que se têm dos apreciadores de cachaça; motivações para o consumo; e o que se entende como " beber uma boa cachaça".

Inicialmente, a divulgação do formulário foi feita indiscriminadamente para que, em um segundo momento, os respondentes pudessem ser selecionados de acordo com o objetivo da pesquisa e seu perfil como consumidor. Para este estudo, o enfoque estava nos degustadores, ou seja, nos consumidores os quais preocupam-se com o momento do consumo. Estes fazem questão de consumir algo de qualidade, que cumpra com as determinações legais, além de seguir as boas práticas de consumo (COUTINHO, 2003). Portanto, tendo as respostas em mãos fizemos a seleção dos respondentes atentando inicialmente a esse perfil de consumidor.

Como critério de seleção, buscou-se selecionar apenas degustadores de cachaça artesanal de alambique. Dos 25 respondentes, foram selecionados apenas 20 para análises posteriores. Destes 7 são mulheres e 13 são homens. Os 5 respondentes excluídos da amostra são aqueles cujo consumo não corresponde a essa proposta, seja por não consumirem exclusivamente cachaça de alambique, apresentarem exceções com relação ao ato de beber e/ou por estarem há muito tempo sem consumir.

Isto posto, observou-se que os respondentes selecionados contam com idades variadas, cuja faixa etária compreende dos 21 aos 40 anos. Em relação à renda mensal familiar, destaca-se que 6 deles recebiam até dois salários mínimos, 6 até três salários mínimos, 4 até quatro salários mínimos e acima de cinco salários. No Quadro 1, são apresentadas informações que permitem compreender características importantes acerca desse tipo de consumo. Todos os nomes reais dos entrevistados foram omitidos, a fim de manter em sigilo os participantes. Por esse motivo, todos os nomes utilizados são fictícios.

Quadro 1 - Caracterização dos entrevistados

\begin{tabular}{|c|c|c|c|}
\hline Nome & Idade & Tempo de Consumo & $\mathbf{R} \$$ por garrafa \\
\hline Gabriel & 41 & 25 anos & 40 reais \\
\hline José & 25 & 7 anos & 30 reais \\
\hline Bianca & 24 & 2 anos & 20 reais \\
\hline Júlio & 25 & 8 anos & 20 reais \\
\hline Leonardo & 40 & $\begin{array}{l}\text { Iniciou com } 13 \text { anos, consome há } \\
27 \text { anos }\end{array}$ & Minigarrafa, de 5 a 10 reais. \\
\hline Gustavo & 34 & 6 anos & 17 reais \\
\hline Lorena & 24 & 3 anos & até 30,00 reais \\
\hline Pablo & 34 & 5 anos & 5 reais \\
\hline Glória & 37 & 3 anos & 40 reais \\
\hline Paula & 30 & $\begin{array}{c}5 \text { anos e } 2 \\
\text { meses }\end{array}$ & 18 reais \\
\hline Humberto & 26 & 12 anos & 20 reais \\
\hline Bento & 33 & Muitos anos já & Não compro, ganho as doses dos \\
\hline
\end{tabular}

RGO - Revista Gestão Organizacional, Chapecó, v. 14, n. 2, p. 46-68, maio/ago. 2021. 
Consumo de cachaça e seus sentidos:

uma análise do comportamento do consumidor à luz da teoria do Sensemaking

\begin{tabular}{|c|c|c|c|}
\hline & & & amigos \\
\hline Luiza & 25 & 6 anos e 6 meses & 20 reais \\
\hline Daniel & 33 & 3 anos & 20 reais \\
\hline Genario & 35 & 5 anos & 5 a 12 reais \\
\hline Isaqui & 27 & 5 anos & $\begin{array}{c}\text { Depende do motivo, para beber de } \\
\text { "galera" 10 reais está bem pago, se for } \\
\text { para presentear já gastei até 70 reais }\end{array}$ \\
\hline Daiane & 26 & 6 anos & 15 reais \\
\hline Sofia & 24 & 4 anos & Nunca comprei \\
\hline Bruno & 28 & 10 anos & 15 reais \\
\hline Felipe & 26 & 1 ano e 4 meses & \\
\hline
\end{tabular}

Fonte: elaborado pelos autores (2020).

A coleta de dados ocorreu durante todo o mês de junho de 2019. O contato com os consumidores se deu principalmente através de redes sociais. Os respondentes residem no Estado de Minas Gerais, em destaque nos municípios de Lavras, Conselheiro Lafaiete e na região metropolitana de Belo Horizonte. Todas as informações obtidas foram mantidas sem quaisquer alterações. Após a seleção dos respondentes e organização dos dados, estes foram analisados por meio da análise de conteúdo.

A análise de conteúdo trabalha sobre mensagens contidas em arquivos, embora também possam ser estudados pela análise documental ou linguística. Delagnello e Silva (2005) listam as etapas da análise de conteúdo se baseando nos estudos de Lawrence Bardin (1970). Logo, destacam-se três momentos: pré-análise; exploração ou análise; e, por fim, inferência e interpretação dos dados. No momento da pré-análise, buscou-se organizar o material proveniente das respostas às questões do formulário, em que foram feitas referências para as questões. Na exploração e análise do material os resultados brutos foram tratados com o intuito de torná-los significativos e válidos. Para isso, abordou-se o conceito bardiniano de codificação em que a escolha das unidades e a classificação dos resultados se deram por meio de categorias definidas com base em grade mista, ou seja, parte das categorias foram definidas a priori, com base na literatura e outra parte surgiu aos pesquisadores por meio das informações dos formulários a posteriori. Dessa forma, as categorias de análise definidas foram adaptadas a partir das sete categorias da teoria da Sensemaking de Weick (1995), apresentadas no Referencial Teórico. São elas: I) Socialização; II) Ambientes Sociais; III) Influenciados; e IV) Crenças e/ou religião. Em relação ao comportamento dos consumidores estabelecemos as seguintes categorias baseadas no referencial teórico, bem como a partir das respostas do formulário: I) Exigentes (SILVA, 2009; OLIVEIRA et al., 2012; BRAGA; KIYOTANI, 2015); II) Conservadores; III) Vínculos sociais; e IV) Poder Aquisitivo (OLIVEIRA et al., 2012; BRAGA; KIYOTANI, 2015).

Por último, na fase de interpretação, há momentos intuitivos e de reflexão, com embasamento nos materiais empíricos e nos referenciais teóricos disponíveis, buscando estabelecer relações, verificar contradições, e, principalmente, compreender os fenômenos relevantes para o estudo. Logo, no tópico a seguir, serão apresentadas as análises e os resultados das informações coletadas no estudo para se compreender o comportamento dos degustadores e os sentidos por eles atribuídos ao consumo de cachaça.

\section{ANÁLISE E RESULTADOS}

Para melhor apresentação das análises e resultados do dados levantados no trabalho foi necessário dividi-lo em dois momentos: o primeiro, relacionado aos sentidos atribuídos à cachaça pelos respondentes, utilizando-se as categorias referentes à teoria de Sensemaking. 
Elisabeth Thaiane Tercino de Araújo, José Kennedy Lopes Silva, Flávia Carolini Pereira dos Santos e Ana Cristina Ferreira

Posteriormente, serão apresentadas as informações analisadas referentes à maneira do consumo dos participantes com base em categorias de análises relacionadas ao Comportamento dos Consumidores.

\subsection{SENTIDOS ATRIBUÍDOS A CACHAÇA}

Inicialmente, tratando da Socialização como um aspecto relevante, foi possível observar que este é um momento no qual os respondentes consomem bebidas com pessoas queridas, principalmente amigos e família. Nesse sentido, destaca-se que o consumo de cachaça se dá como uma oportunidade de promover a integração social entre os indivíduos, tendo em vista que ela é consumida para "conversar com amigos" (José), "para diversão com amigos" (Bianca), "interação com o grupo" (Luiza), "selar novas amizades" (Daiane). Daiane complementa dizendo que a cachaça é consumida por muitas pessoas de seu círculo social, como uma "forma de socialização, por isso, é normal ouvir um "vamos virar uma branquinha" quando acaba de se conhecer alguém". Esse aspecto do consumo atrelado à ideia de socialização se relaciona com o que Weick (1995) ressalta acerca do sensemaking, isto é, a construção de sentido nunca é fruto de um só indivíduo, pois se considera que a ação e/ou inação de um implica diretamente nos outros.

É importante observar que o consumo está recorrentemente associado a um ambiente de descontração e intimista. A esse respeito, Felipe afirma que a cachaça é "uma bebida para desfrutar entre amigos com um bom papo". Nesse sentido, Daiane também comenta que, por conveniência ou pressão dos grupos sociais nos quais convive, acaba consumindo. Bruno, por sua vez, justifica seu consumo por cachaças mais baratas aos efeitos que a bebida provoca, socialmente falando. A partir de suas falas, é notório que não há uma preocupação com a qualidade do produto, tendo em vista que a consome para perder a timidez e facilitar a socialização com outros indivíduos. Por isso, quando está entre amigos, Bruno "prefere beber a cachaça mais barata" com o intuito de realmente confraternizar nesses momentos especiais. Com isso, percebe-se que se distanciam de um consumo orientado pela diversidade que contempla as exigências dos vários estilos e culturas dos consumidores em potencial e dos amantes da caninha brasileira (BRAGA; KIYOTANI, 2015). Desse modo, a relação estabelecida entre os indivíduos pressupõe uma relação intersubjetiva, cujos interesses, gostos, preferências, marcas e significados sociais desses indivíduos se mesclam através da prática consumista (RETONDAR, 2008).

Os momentos em que ocorrem esse consumo estão diretamente relacionados à diversão, à troca de experiências, a novos contatos e a um bom papo. Ocasiões específicas, como eventos comemorativos, foram citadas como os principais momentos que ocorrem o consumo e as trocas estabelecidas a partir desse consumo, conforme as afirmações de Lorena, Bento e Isaqui. Diante desses apontamentos, Ferreira et al. (2018) reforçam que as trocas estabelecidas no ato do consumo são extremamente significativas, assim como o produto.

Além disso, destaca-se que, em alguns relatos, a cachaça é consumida de uma outra forma, isto é, a bebida é utilizada para drinks e a famosa caipirinha. Lorena comenta que seu consumo se dá basicamente na forma de drinks, cuja experiência está muito mais atrelada à degustação e ao consumo consciente da bebida. Cachaças de sabor, como a de milho, por exemplo, foram destacadas como novas possibilidades, tendo em vista que seu consumo é moderado e acontece mais no sentido da apreciação. Isaqui destaca que procura por cachaças que "apresentem certo aspecto de suavidade no sabor, muitas vezes acompanhada por outro produto, como mel". Sofia, por sua vez, comenta que seu consumo geralmente se dá na forma de caipirinha, pois, embora aprecie uma cachaça de qualidade, opta por bebidas de sabor mais 
Consumo de cachaça e seus sentidos:

uma análise do comportamento do consumidor à luz da teoria do Sensemaking

leve e adocicado.

Nesse sentido, foi possível perceber duas outras categorias relacionadas a essas questões, são elas: Ambientes Sociais e Influenciados. Diante da afirmação de Júlio que ressalta o consumo da bebida como uma tradição familiar e social, pressupõe-se que os ambientes sociais, os quais ele frequenta, principalmente com os familiares, o influencia diretamente a consumir a bebida. Além disso, Leonardo também aponta que a tradição familiar é um fator que o estimula ao consumo em ambientes nos quais os membros de sua família estão presentes. Desse modo, faz parte da construção de sentido o processo interpretativo, no qual se torna possível julgar as experiências vivenciadas, as ações e o próprio senso de identidade em relação a outros específicos e generalizados (CUNLIFFE; COUPLAND, 2016). Barros (2006) e Pinto e Batinga (2016) ainda chamam atenção para esse aspecto ao elucidar que a individualidade de cada ator está inserida em um conjunto interligado de relações sociais e culturais. Isaqui sustenta o argumento de que as pessoas, que detém principalmente um capital cultural simbólico devido à tradição familiar, consome cachaça de forma similar ao consumo do vinho.

Bento comenta que não possui o hábito de consumir cachaça, no entanto, entre amigos se permite consumi-la sob a influência de indivíduos que gostam de uma caninha e a consomem por prazer. Ele ainda complementa ressaltando que ele bebe cachaça sobretudo sob a influência de outrem. Daiane afirma que no seu meio social é notório que nos grupos sociais formados, o consumir cachaça se torne um ritual do qual todos os "recém chegados" devem participar. Ela destaca que essa é uma forma de "selar uma amizade". A partir desse relato fica evidente que em determinados ambientes sociais, o consumo da bebida é uma forma de Socialização a qual impõem que para a socialização e integração dos indivíduos, todos devem consumir a bebida. Weick (1995) elucida essa questão dos ambientes sociais ao considerar que esses ambientes são naturalmente dinâmicos, ativos, mutáveis e sofrem a influência direta das pessoas. São elas que compõem esses espaços e são as principais causas desse movimento constante.

Entretanto, Leonardo afirma que quando mais jovem tomava uma pequena dose antes do jantar, como tradição de família. No entanto, a sua crença atual o impede de estar em ambientes onde o consumo é disseminado e faz parte desse processo de socialização dos indivíduos. Analisando suas respostas sob essa perspectiva, foi possível observar que embora sua crença o limite acerca do consumo de bebidas alcoólicas, Leonardo gosta de cachaça. Contudo, destaca-se que para consumir a bebida, bem como manter sua tradição familiar, ele adequou suas práticas para um consumo mais moderado e responsável, conforme disse nos questionamentos. Ressalta-se que os Ambientes Sociais, religiosos principalmente, são determinantes para as práticas de consumo. Allard-Poesi (2005) argumenta que o sensemaking pode ser impulsionado por crenças ou por ações, considerando que as crenças moldam o que as pessoas veem e dão forma às ações que elas realizam. Mesquita (2007) chama atenção para esse ponto ao citar que se identifica a atuação do corpo eclesiástico como mediador da construção dos valores que constituem respostas espiritual e social aos desejos e anseios dos fiéis.

Para classificar os sentidos atribuídos pelos consumidores de cachaça, foi necessário relacionar as qualidades relatadas pelos investigados para que se pudesse compreender com profundidade o que eles dizem em relação aos sentimentos manifestados em relação ao consumo de cachaça. Diante do exposto, foi possível notar que essas categorias, embora delineadas teoricamente, relacionam-se bastante do ponto de vista empírico. De acordo com as respostas dos participantes, pode-se perceber que as categorias Socialização, Ambientes 
Elisabeth Thaiane Tercino de Araújo, José Kennedy Lopes Silva, Flávia Carolini Pereira dos Santos e Ana Cristina Ferreira

Sociais, Influenciados e Crenças e/ou religião estão bastante presentes nas falas e corroboram sobretudo as concepções de significados e a construção de sentidos ao que tange o consumo de cachaça. Nesse sentido, compreende-se que como processo interpretativo, há um autojulgamento das experiências, ações e senso de identidade do ponto de vista individual, para que, posteriormente, seja feita uma comparação em relação a outros grupos específicos (CUNLIFFE; COUPLAND, 2016), nesse caso outros consumidores de cachaça. Nota-se que o consumo dos respondentes está diretamente relacionado aos ambientes sociais em que estão, uma vez que as crenças e valores compartilhados entre os indivíduos atuam como um limitador ou facilitador do consumo. Entretanto, observou-se que muitos respondentes sentem uma maior permissividade em relação ao seu próprio consumo utilizando a bebida em muitos momentos como um elemento facilitador das relações entre grupos. Portanto, a construção de sentido é o principal local onde os significados se materializam, informam e restringem a identidade e a ação (WEICK; SUTCLIFFE; OBSTFELD, 2005).

Para compreender como se dá a relação entre os sentidos atribuídos pelos consumidores investigados será apresentado no próximo tópico deste trabalho como eles se comportam em relação à cultura do consumo de cachaça.

\subsection{COMPORTAMENTO DOS CONSUMIDORES DEGUSTADORES DE CACHAÇA ARTESANAL PRODUZIDA EM ALAMBIQUE}

Os respondentes relacionaram sua perspectiva principalmente ao que eles priorizam em uma cachaça que, em síntese, são: sabor (gosto), qualidade e valor monetário. Para Lorena, é importante analisar para a escolha da cachaça, "seu sabor e concentração alcoólica, procurando sempre uma mais suave e doce". Já Isaqui também se preocupa com o sabor da cachaça ao dizer que procura "cachaças que apresentem certo aspecto de suavidade no sabor, muitas vezes acompanhada por outro produto, como mel". Para Quintão, Brito e Belk (2017), a discussão do gosto como uma atividade reflexiva, é cultural e estudado, requer desempenho por parte dos consumidores para participarem de determinados espaços sociais e culturais.

Em relação à qualidade, os consumidores relacionam essa característica à cachaça artesanal, conforme relata Sofia e Gabriel, os quais consomem marcas de cachaças artesanal e vinculam a preferência dessas marcas à qualidade. Para Gabriel, a cachaça tem que ter "qualidade artesanal" e Sofia procura "cor, qualidade e odor". Já Humberto e Luiza, além de terem conhecimento de diversas marcas de cachaças, preocupam-se com preço e qualidade. Quando os participantes supracitados elencam suas prioridades de sabor (gosto), qualidade e preço das cachaças como sendo os principais fatores analisados, demonstram serem Exigentes em suas escolhas e decisões sobre a bebida. De acordo com Ferreira et al. (2018, p. 31), consumidores exigentes são aqueles "que analisam os produtos que irão consumir, buscando um produto de qualidade e com as características necessárias". Silva (2009), Oliveira et al. (2012) e Braga e Kiyotani (2015), argumentam sobre a cachaça que os consumidores buscam pela bebida de qualidade, com as características sensoriais que lhes são consideradas adequadas, levando-os a apreciadores mais Exigentes.

Os consumidores participantes se mostraram Conservadores que, por algum motivo, baseiam suas crenças para decidirem beberem ou não a cachaça. Em relação ao consumo de cachaça por homens e mulheres, os respondentes afirmaram que a bebida está relacionada ao sexo masculino, o que se caracteriza, de certa maneira, uma posição estereotipada e vinculada ao sabor e à cultura da cachaça. Registra-se, aqui, a fala de Luiza: "É culturalmente mais consumida por homens. Além disso, o sabor também influencia nas preferências". Já Genario, além de fazer referência à cultura da cachaça por ser consumida por homens, 
Consumo de cachaça e seus sentidos:

uma análise do comportamento do consumidor à luz da teoria do Sensemaking

acredita que o consumo por parte de mulheres vem aumentando, "porém vem tendo uma alteração nos últimos tempos, o que é bom para o setor".

$\mathrm{Na}$ fala de Daiane fica caracterizado o conservadorismo ainda presente entre os consumidores de cachaça e o sentido que eles dão ao consumo de cachaça relacionado ao sexo masculino. Na fala da entrevistada:

Eu acho que mais por homens, normalmente as mulheres que tomam cachaça são
divididas entre as 'brutas' e as 'que dão trabalho'. Enquanto que, para os homens, o
consumo de cachaça faz parte da inclusão social. Claramente essa resposta vem da
minha percepção a partir da minha bolha. Quando penso na minha família é
inadmissível uma menina tomar cachaça (Daiane).

Nesse contexto apresentado, é importante relacionar às discussões de Bertuol et al. (2017) em que, para os autores, o consumo representa que indivíduos são capazes de interpretar os sentidos. Relacionou-se a este processo conservador sobre gênero a discussão de McCracken (2007) e Toni, Larentis e Mattia (2012) sobre o aspecto cultural dos consumidores de cachaça. Assim, é importante que os produtores de cachaças, os praticantes de marketing e os consumidores avaliem esse processo para que seja possível modificar esse aspecto cultural relacionado ao consumo de cachaça por partes das mulheres e a masculinidade tratada por Zanella (2011), ao reconhecer que se trata de relações socialmente construídas entre homens e mulheres e as diferenças entre a "maneira de beber", que se refere às práticas de significados, e o autocontrole ao ato de consumir bebida alcóolica.

Com relação aos Vínculos Sociais, estes aparecem quando os respondentes dialogam porque bebem cachaça. Por exemplo, José bebe cachaça para reunir os amigos e a Daiane para selar novas amizades. Os vínculos sociais se caracteriza por um "grupo de consumidores denominados por eles mesmos de "tribos", compartilham experiências e identidades comuns" (FERREIRA et al., 2018, p. 31). Ademais, a maioria dos respondentes não frequenta cursos ou exposições. Somente seis apreciadores já foram em alguma feira ou tiveram uma única experiência, como é o caso de Bianca e Isaqui. Dessa forma, Ferreira et al. (2018, p. 31) explicam que "os produtos são consumidos pelo seu significado e são importantes marcadores de posição social".

A Posição Social está presente também na definição da categoria Poder Aquisitivo. Os respondentes possuem, em geral, uma renda acima de um salário mínimo e tendem a gastar, em média, $\mathrm{R} \$ 20,00$ reais. Daniel, por exemplo, foi um dos participantes que mais paga por uma garrafa de cachaça chegando a quantia de $\mathrm{R} \$ 90,00$. A participante Daiane, que paga para consumo somente $\mathrm{R} \$ 10,00$ reais, chega a presentear um ente querido com uma garrafa de $\mathrm{R} \$ 70,00$ reais. Por outro lado, os apreciadores tendem a julgar quem bebe a cachaça industrial por pensar que são pessoas de uma classe inferior a deles. O participante Felipe explica algo comum aos consumidores da cachaça artesanal ao argumentar que "como todo produto artesanal, as pessoas que trabalham e têm maior renda que consomem a cachaça mais cara". A respondente Luiza faz um recorte similar ao dizer que os apreciadores de cachaça são, para ela, pessoas refinadas e exigentes. José, por sua vez, afirma que "Pobre gosta de cachaça. Rico gosta de Whisky ou cachaça cara!". Isaqui complementa ao inserir indivíduos universitários de classe alta que consomem a cachaça chamada "aguardente": "acredito que há uma divisão de consumo [...]. A cachaça (aguardente) é consumida pela classe baixa, mas também por jovens universitários [...]. Já a cachaça artesanal é consumida por uma classe que possui capital financeiro maior".

Nesse sentido, é possível notar que o consumo de cachaça artesanal é tido como um status. Essas informações corroboram as discussões apresentadas por Oliveira et al. (2012) e 
Elisabeth Thaiane Tercino de Araújo, José Kennedy Lopes Silva, Flávia Carolini Pereira dos Santos e Ana Cristina Ferreira

Braga e Kiyotani (2015) quando reforçam que a preparação mais minuciosa e rigorosa tornam a cachaça artesanal um produto com uma melhor elaboração, e, assim, um produto de maior valor agregado. Além disso, esse pensamento remete a ideia de valorização da cachaça, em especial a produzida em alambiques, uma vez que esse aspecto do poder aquisitivo e status apresentam um significado importante para alguns consumidores. Dessa maneira, não há como negar que, na construção social da atualidade, as identidades dos cidadãos se configuram, também, pelo consumo, de modo que o status, muitas vezes, pode ser medido pelo que se consome (COSTA; TEODÓSIO, 2011).

Nesse estudo identificamos dois aspectos importantes, são eles: as categorias de análise e as perspectivas de consumo. Isto posto, viu-se que a partir dos dados e análises coletados nas respostas dos participantes da pesquisa, é possível relacionar as categorias de sentidos atribuídos - socialização, ambientes sociais, influenciados e crenças e/ou religião - às de perspectivas de consumo, exigentes, conservadores, vínculos sociais e poder aquisitivo, conforme apresentado na Figura 1.

A relação estabelecida neste trabalho é evidenciada na Figura 1, baseia-se inicialmente no pressuposto teórico acerca do sensemaking. Isto é, sendo a construção dos sentidos fruto da interpretação e explicação dos aspectos sobre o seu ambiente, os indivíduos se dedicam à criação de ordem e sentido retrospectivo a determinada experiência (JEONG; BROWER, 2008; MUNCK, 2015). Diante disso, como sentidos foram definidos elementos os quais estiveram fortemente presentes nas respostas os degustadores. O próprio termo utilizado resume posicionamentos mais gerais acerca da cachaça e do seu consumo sob a perspectiva deles. Todavia, observou-se que esses sentidos estavam atrelados a determinadas características, perfis e aspectos desse consumo. Logo, o sentido concebido pelos degustadores perpassam uma análise de si como apreciadores da bebida e das experiências que possuem nesse momento do consumo.

Figura 1 - Relação entre as categorias de sensemaking e as perspectivas do consumo cultural

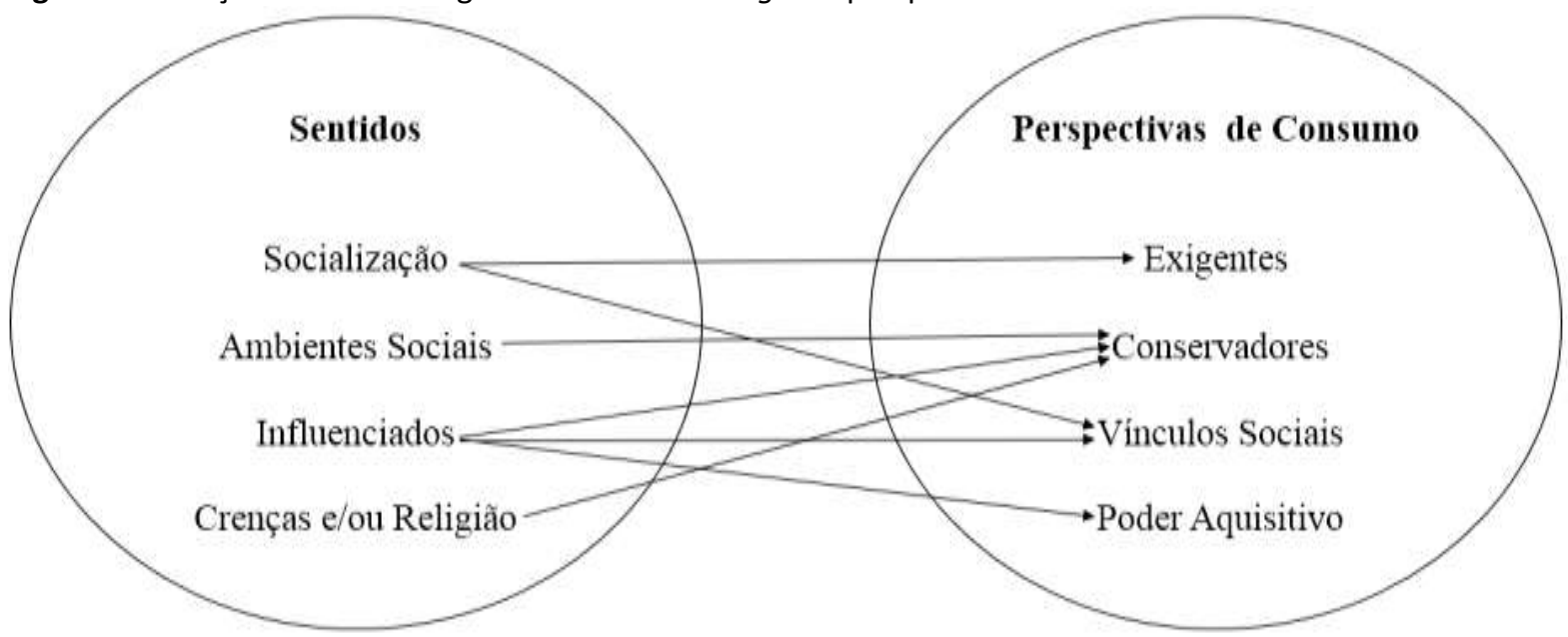

Fonte: elaborado pelos autores (2020).

Os atributos de sentido que mais se destacam entres os respondentes são o da Socialização e ambientes sociais, e o comportamento é o do fortalecimento dos Vínculos Sociais. Os consumidores pesquisados valorizam a socialização e o vínculo que o consumo de cachaça lhe oferecem e que os consumidores também se comportam de maneira rigorosa 0 que se caracteriza o comportamento Exigente, pois valorizam a qualidade e origem do produto e são conservadores principalmente em relação ao consumo das mulheres.

Os atributos de Ambiente Social e Crenças e/ou Religião se relacionam com o 
Consumo de cachaça e seus sentidos:

uma análise do comportamento do consumidor à luz da teoria do Sensemaking

comportamento Conservadores, nesse contexto, foi possível identificar como hábitos de consumo que estão relacionados ao fortalecimentos dos hábitos conservadores dos consumidores. Apesar de se perceber uma transformação desses ambientes relacionados ao consumo, principalmente relacionados ao ato de beber cachaça artesanal, o conservadorismo ainda é nítido nas relações de consumo de cachaça sobretudo a cachaça industrial.

$O$ atributo Influenciados ficou relacionado a três comportamentos, Conservadores, Vínculos Sociais e Poder Aquisitivo. Isto é, confirmado, pois os respondentes demonstram ter comportamentos, haja vista que consomem cachaça devido aos hábitos tradicionais que envolvem o produto, pelas relações sociais que são construídas e fortalecidas por meio de uma identidade de consumo e também pelo poder aquisitivo desses grupos tanto no consumo de cachaça industrial quanto no artesanal. Em suma, estão fortemente relacionadas as categorias de sensemaking Socialização e Influenciados ao comportamento de Vínculos Sociais, e a categoria Ambientes Sociais ao comportamento de consumo Conservadores.

A partir dessas análises sobre os sentidos atribuídos pelos apreciadores de cachaça e a possibilidade de compreender o seu comportamento, é apresentada a conclusão do trabalho, apontando os principais resultados, as limitações, contribuições empíricas e teóricas e as sugestões de pesquisas futuras.

\section{CONSIDERAÇÕES FINAIS}

Os principais resultados desta pesquisa mostraram que os sentidos atribuídos ao consumo de cachaça artesanal confluem também para o comportamento dos degustadores da bebida. Após a coleta de dados, foi realizada a análise de conteúdo temática. As primeiras categorias foram baseadas na própria teoria, a partir dos preceitos delineados por Weick (1995). Dessa forma, foram apresentadas as categorias socialização, ambientes sociais, influenciados e crenças e/ou religião. No segundo momento da análise, foram distribuídas novas categorias baseadas nas respostas e na exposição teórica sobre comportamento do consumidor. Foram identificadas mais quatro categorias que caracterizam os diferentes tipos de consumidores, descritos, posteriormente, como exigentes, conservadores, que consomem por vínculos sociais e/ou com preferências de consumo influenciadas por questões financeiras.

Os resultados da pesquisa apontaram que os apreciadores bebem a cachaça e atribuem ao seu consumo um momento de socialização com outrem em ambientes específicos, como, por exemplo, eventos e confraternizações. Dessa forma, o consumo dessas pessoas está relacionado diretamente à socialização, bem como à diversão, à troca de experiências, a novas amizades e oportunidades de se manter um bom diálogo. Os indivíduos tendem a consumir drinks, como a famosa caipirinha ou a cachaça com mel, por exemplo. Isso evidencia que coquetéis são também uma oportunidade de se consumir o destilado.

Outro ponto levado em consideração nas análises é que os apreciadores começaram a consumir em ambientes familiares como forma de perpetuar uma tradição. Nesses casos, o consumo da bebida está atrelado inclusive a um aspecto cultural. Entretanto, outros degustadores comentam que sua experiência de consumo é fortemente influenciada por suas crenças, especialmente as religiosas. Em relação a esse aspecto, nota-se que o momento do consumo é orientado inclusive pelos grupos os quais compartilham dessa prática, isto é, se estes comungam de suas crenças e religião e do prazer em consumir o destilado.

Quando o olhar da pesquisa se aproximou do comportamento dos consumidores, os resultados mostraram que estes são exigentes quanto ao sabor, à qualidade e ao preço da 
Elisabeth Thaiane Tercino de Araújo, José Kennedy Lopes Silva, Flávia Carolini Pereira dos Santos e Ana Cristina Ferreira

cachaça. Além disso, observou-se um olhar pouco mais conservador com relação à diferenciação de consumo entre homens e mulheres. Esse aspecto pode inclusive demonstrar o quão limitado é o olhar sobre o perfil dos consumidores. A maioria dos respondentes não frequenta feiras e exposições de cachaça, com isso, pode-se compreender que os degustadores investigados neste trabalho não costumam prestigiar eventos específicos cujos participantes não são só apreciadores, mas também curiosos da bebida. Portanto, o vínculo social não é forte se comparado a outros grupos de consumidores, por exemplo. Em contrapartida, os vínculos sociais se destacaram quando os respondentes afirmaram beber para se socializar e estar entre os amigos. Esse é um aspecto que aparece de modo significativo nas respostas obtidas. Por fim, quanto ao poder aquisitivo, observou-se que existem pessoas capazes de pagar uma quantia maior por uma garrafa de cachaça, enquanto outros relacionam o preço baixo da cachaça aos consumidores de baixa renda e à aguardente como uma bebida inferior. Nesse sentido, nota-se que o estigma ainda está presente no imaginário das pessoas, o que evidencia que a cachaça ainda é vista como uma bebida consumida e apreciada por indivíduos de baixa pecúnia.

Após o fechamento das análises, considerou-se que, nesta pesquisa, também há limitações que podem ser melhoradas em pesquisas futuras. Quanto à limitação teórica, identificou-se que, na literatura científica, McCracken (2007) discute o ritual como um importante processo para manipular o significado cultural. O ritual, segundo o autor, é usado para o movimento dos consumidores dentro das categorias culturais. São quatro tipos de rituais: troca (natal e aniversário), posse (fotografia e personalização dos produtos), cuidados pessoais (rituais e preparação para sair) e alienação. $O$ autor argumenta que é interessante pesquisar o comportamento do consumidor pelo ponto de vista do ritual, o que não foi considerado nesta pesquisa.

Outra limitação é que não é possível generalizar os resultados desse trabalho devido a pouca representatividade numérica dos formulários respondidos. No entanto, os resultados do trabalho devem ser considerados como uma demonstração de como se comportam os apreciadores de cachaça artesanal. Outro ponto, também, é que não se ponderou, neste trabalho, o consumo consciente da cachaça. Ademais, não se analisou a percepção dos consumidores pesquisados com relação à bebida, visto que se optou por verificar os sentidos e o comportamento dos degustadores de cachaça artesanal de alambique.

Este estudo faz contribuições empíricas em relação às pesquisas sobre os consumidores de cachaça de alambique, especialmente ao que tange às análises e contribuições para os próprios produtores da bebida. Isso lhes permitem fazer uma leitura sobre o comportamento dos degustadores de cachaça, quais os sentidos atrelados ao consumo do destilado e quais os aspectos que podem influenciar diretamente suas práticas. Além disso, novas abordagens do Marketing podem ser utilizadas com o intuito de alcançar esse público mais atento à bebida, bem como despertar determinados significados, sentimentos e sentidos através de rótulos, propagandas, posicionamento de marcas, dentre outros elementos. Em relação às contribuições teóricas, este estudo avança na aproximação teórica dos estudos de Sensemaking e as pesquisas em comportamento de consumidor e Marketing. O fato de trabalhar o sensemaking nessa perspectiva já contribui com um novo olhar sobre os estudos de Marketing, sobretudo pela importância dada ao aspecto mais subjetivo dos consumidores.

Como sugestões de pesquisas futuras, propõe-se um estudo capaz de interpretar a percepção dos consumidores sobre a cachaça artesanal e as práticas que permeiam essa experiência. Nesse sentido, Campomar (2006) apresenta que a palavra 
Consumo de cachaça e seus sentidos:

uma análise do comportamento do consumidor à luz da teoria do Sensemaking

"percepção" é importante para as pesquisas em Marketing, uma vez que o conceito da palavra está sendo cada vez mais deturpado nesse campo de estudos. Além disso, tendo em vista a questão de gênero brevemente tratada nas discussões, considera-se de suma importância compreender como as mulheres têm atuado no campo da cachaça não só na condição de potenciais consumidoras, mas também como produtoras e empresárias do setor.

As considerações finais deste trabalho reforçam a importância da produção de pesquisa qualitativa na área do marketing. Além disso, reconhece-se o papel da cachaça como produto genuinamente nacional, sobretudo como promissor objeto de estudos nas pesquisas científicas. Notadamente, constitui-se como desafio as produções qualitativas nas áreas de Marketing e a adoção de um objeto cujas pesquisas ainda são pouco exploradas no cenário nacional. Desse modo, os resultados e contribuições deste trabalho visam trazer novos caminhos para a pesquisa do Marketing e comportamento do consumidor, bem como evidenciar que existem diversos objetos culturalmente valiosos para o Brasil a serem trabalhados.

\section{REFERÊNCIAS}

ALLARD-POESI, F. The Paradox of Sensemaking in Organizational Analysis. Organization, v. 12, n. 2, p. 169-196, 2005. DOI: https://doi.org/10.1177/1350508405051187.

ANDRADE, L. P.; ANDRADE, L. F. A. Cachaça sob uma perspectiva histórica, cultural e simbólica. In: SEMINÁRIOS EM ADMINISTRAÇÃO, 18., 2015, São Paulo, Anais eletrônicos [...] São Paulo: USP, 2015. Disponível em:

http://sistema.semead.com.br/18semead/resultado/trabalhosPDF/1338.pdf. Acesso em: 20 maio 2019.

BARROS, C. Consumo, Hierarquia e Mediação: Um estudo antropológico no universo das empregadas domésticas. In: ENCONTRO DA ASSOCIAÇÃO NACIONAL DE PÓS-GRADUAÇÃO E PESQUISA EM ADMINISTRAÇÃO , 30., 2006, Salvador, Anais eletrônicos [...] Salvador: ANPAD, 2006. Disponível em:

http://www.anpad.org.br/diversos/down_zips/10/enanpad2006-mktb-3046.pdf. Acesso em: 03 mar. 2020.

BARBOSA, L.; CAMPBELL, C. O estudo do consumo nas ciências sociais contemporâneas. In: BARBOSA, L.; CAMPBELL, C. (Orgs.). Cultura, consumo e identidade. Rio de Janeiro: Editora FGV, p. 21-44, 2006.

BAUDRILLARD, J. A sociedade de consumo. Lisboa: Edições 70, 1995.

BAUMAN, Z. Vida para consumo: a transformação das pessoas em mercadoria. Rio de Janeiro: Jorge Zahar, 2008.

BERTUOL, M.; SAMPAIO, C. H.; PERÍN, M. G.; VIEIRA, M. H. Uma análise dos significados de consumo de vinho no contexto de uma confraria feminina. Revista de Administração da UFSM, Santa Maria, v. 10, n. 2, p. 265- 287, 2017. DOI:

https://doi.org/10.5902/1983465912672. 
Elisabeth Thaiane Tercino de Araújo, José Kennedy Lopes Silva, Flávia Carolini Pereira dos Santos e Ana Cristina Ferreira

BORGES, A. F.; TAKEMOTO, S. N. C. Inovação no setor de cachaça artesanal: estudo de caso. Revista Pensamento Contemporâneo em Administração, v. 13, n. 1, p. 79-99, 2019. DOI: http://dx.doi.org/10.12712/rpca.v13i1.27479.

BRAGA, M. V. F.; KIYOTANI, I. B. A cachaça como patrimônio: turismo, cultura e sabor. Revista de Turismo Contemporâneo, Natal, v. 3, n. 2, p. 254- 275, 2015.

BROWN, A. D.; COLVILLE, I.; PYE, A. Making Sense of Sensemaking in Organization Studies. Organization Studies, v. 36, n. 2, p. 265-277, 2015. DOI: https://doi.org/10.1177/0170840614559259.

CAMPOMAR, M. C. Pesquisa em marketing e seus problemas versus pesquisa de marketing. Gestão.Org, Recife, v. 4, n. 2, 2006.

CAMPOS, R. D.; NASCIMENTO, T.; PINHO, V. de. Preparando o caminho para a chegada da Consumer Culture Theory. In: PINTO, M. de R. ; BATINGA, G. L. (Org.). Cultura e consumo no Brasil: estado atual e novas perspectivas. Belo Horizonte: PUC-Minas, 2018. p. 31-58.

CARDOSO, M. G.; CAMPOS, G. A.; SILVA, R. A. Da; SANTOS, C. D. Dos; PINTO, A. P. S.; SILVA, C. F. Cachaça: Qualidade e Produção. Boletim de Extensão, publicado pela Pró Reitoria de Extensão, UFLA, 2005.

CASCUDO, L. C. Prelúdio da cachaça. Global Editora e Distribuidora Ltda, 2014.

CHALITA, M. A. N. A construção social e econômica do gosto e da preferência, o valor simbólico da mercadoria e o desempenho das exportações de cachaça. Informações Econômicas, São Paulo, v. 38, n. 5, 2008.

CORREA, M. V. P.; RESE, N.; SANDER, J. A.; FERREIRA, J. M. O papel do sensemaking nos processos de mudança nas organizações. In: ENCONTRO DE ESTUDOS ORGANIZACIONAIS DA ANPAD, 8., 2014, Gramado. Anais eletrônicos [...] Gramado: ANPAD, 2014. Disponível em: http://www.anpad.org.br/admin/pdf/2014_EnEO162.pdf. Acesso em: 04 jun. 2019.

COSTA, D. V. da; TEODÓSIO, A. dos S. de S. Desenvolvimento Sustentável, consumo e cidadania: um estudo sobre a (des) articulação da comunicação de organizações da sociedade civil, do Estado e das empresas. Rev. Adm. Mackenzie, São Paulo, v. 12, n. 3, p. 114-145, 2011. DOI: https://doi.org/10.1590/S1678-69712011000300006.

COUTINHO, E. P. Práticas ultrapassadas e mitos de qualidade na cadeia de produção de cachaça artesanal. In: ENCONTRO NACIONAL DE ENGENHARIA DE PRODUÇÃO, 23., 2003, Ouro

Preto. Anais eletrônicos [...] Ouro Preto: ENEGEP, 2003. Disponível em: http://www.abepro.org.br/biblioteca/enegep2003_tr0111_0119.pdf. Acesso em: 07 jul. 2019.

CUNLIFFE, A.; COUPLAND, C. From hero to villain to hero: making experience sensible through embodied narrative sensemaking. Human Relations, v. 65, p. 63-88, 2016. DOI: 
Consumo de cachaça e seus sentidos:

uma análise do comportamento do consumidor à luz da teoria do Sensemaking

https://doi.org/10.1177/0018726711424321.

CZARNIAWSKA, B. Karl Weick: concepts, style, reflection. Theory, Oxford, Blackwell, p. 267278, 2005. In: JONES, Campbell; MUNRO, Rolland (Org.). Contemporary organization theory. Oxford: Blackwell, 2005. p. 267-278.

DELLAGNELO, E. H. L.; SILVA, R. C. da. Análise de conteúdo e sua aplicação em pesquisa na administração. In: VIEIRA, M. M. F.; ZOUAIN, D. M. (Org.). Pesquisa qualitativa em administração: teoria e prática. Rio de Janeiro: Editora FGV, 2005, p. 97-118.

DUARTE, M. de F.; ALCADIPANI, R. Contribuição do organizar (organizing) para os estudos organizacionais. O\&S, Salvador, v. 23, n. 76, p. 57-72, 2016. DOI: https://doi.org/10.1590/1984-9230763.

FERREIRA, A. C.; PEREIRA, M. M. O.; REZENDE, D. C.; VIEIRA, A. S. Simbolismo e Construção da Identidade por meio do Consumo de Cerveja Artesanal. Revista de Negócios, Blumenau, v. 23, n. 3, p. 19-35, 2018. DOI: http://dx.doi.org/10.7867/1980-4431.2018v23n3p19-35.

HOLBROOK, M. B.; HIRSCHMAN, E. C. The experiential aspects of consumption: Consumer fantasies, feelings, and fun. Journal of Consumer Research, v. 9, p. 132-140, 1982.

HOLT, R.; CORNELISSEN, J. Sensemaking revisited. Management Learning, v. 45, n. 5, p. 525539, 2014. DOI: https://doi.org/10.1177/1350507613486422.

HULTIN, L. E.; MÄHRING, M. How practice makes sense in healthcare operations: studying sensemaking as performative, material-discursive practice. Human Relations, Vol. 70, n. 5, p.566-593, 2017. DOI: https://doi.org/10.1177/0018726716661618.

JEONG, H.; BROWER, R S. Extending the Present Understanding of Organizational Sensemaking: Three Stages and Three Contexts. Administration \& Society, v. 40, n. 3, p. 223252, 2008. DOI: https://doi.org/10.1177/0095399707313446.

LOURENÇO, C. D. S.; FERREIRA, P. A.; ROSA, A. R. Etnografia e grounded theory na pesquisa de marketing de relacionamento. RAM, São Paulo, v. 9, n. 4, edição especial, p. 99-124, 2008. DOI: http://dx.doi.org/10.1590/S1678-69712008000400007.

MCCRACKEN, G. Culture and Consumption: A Theoretical Account of the Structure and Movement of the Cultural Meaning of Consumer Goods. Journal of Consumer Research, v. 13, n. 1, p. 71-84, 1986. DOI: https://doi.org/10.1086/209048.

MCCRACKEN, G. Cultura e consumo: novas abordagens ao caráter simbólico dos bens e das atividades de consumo. Rio de Janeiro: Mauad, 2003.

MCCRACKEN, G. Cultura e consumo: uma explicação teórica da estrutura e do movimento do significado cultural dos bens de consumo. Revista de Administração de Empresas, v.47, n.1, São Paulo, p. 99-115, 2007. DOI: https://doi.org/10.1590/S0034-75902007000100014. 
Elisabeth Thaiane Tercino de Araújo, José Kennedy Lopes Silva, Flávia Carolini Pereira dos Santos e Ana Cristina Ferreira

MCCRACKEN, G. Cultura e Consumo II: mercados, significados e gerenciamento de marcas. Rio de Janeiro: Mauad, 2012.

MESQUITA, W. A. B. Um pé no reino e outro no mundo: consumo e lazer entre pentecostais. Horiz. antropol., Porto Alegre , v. 13, n. 28, p. 117-144, 2007. DOI: .

MINISTÉRIO DA AGRICULTURA, PECUÁRIA E ABASTECIMENTO - MAPA. A cachaça no Brasil: dados de registros de cachaças e aguardentes. Brasília, 2019. Disponível em: https://www.gov.br/agricultura/pt-br/assuntos/inspecao/produtos-vegetal/pastapublicacoes-DIPOV/anuario-cachaca.pdf/view. Acesso em: 07 abr. 2020.

MONTENEGRO, L. M.; CASALI, A. M. O modelo de organizing de Karl Weick e sua ênfase na comunicação. In: ENCONTRO DE ESTUDOS ORGANIZACIONAIS, 5., 2008, Belo Horizonte, Anais eletrônicos [...] Belo Horizonte: ANPAD,, 2008. Disponível em: http://www.anpad.org.br/admin/pdf/EnEO136.pdf. Acesso em: 07 ago. 2019.

MORAIS, R.; BRITO, V. G. P.; BRITO, M. J.; PINHEIRO, D. C. Interruption of Informality in Artisanal Cachaça: An Analysis from the Perspective of Institutional Work. Contextus Revista Contemporânea de Economia e Gestão, v. 18, n. 1, p. 107-122, 2020. DOI: https://doi.org/10.19094/contextus.2020.43574.

MUNCK, L. Gestão da sustentabilidade em contexto organizacional: integrando sensemaking, narrativas e processo decisório estratégico. O\&S, Salvador, v. 22, n. 75, p. 521-538, 2015. DOI: https://doi.org/10.1590/1984-9230753.

NATT, E. D. M.; BARBOSA, B. F.; VIEIRA, F. G. D.; CARRIERI, A. de P. Baixa renda: o consumo simbólico e o comércio informal de acessórios femininos. Revista Administração em Diálogo, São Paulo, v. 19, n.1, p. 138-163, 2017. DOI: https://doi.org/10.20946/rad.v19i1.23387.

OLIVEIRA, A. M. L. de. O processo de produção da cachaça artesanal e sua importância comercial. 2010. Monografia (Pós - Graduação em Microbiologia) - Universidade Federal de Minas Gerais: Belo Horizonte, 2010.

OLIVEIRA, E. R. A. “Marvada Pinga”: produção de cachaça e desenvolvimento em Salinas, Norte de Minas Gerais. 2000. Dissertação (Mestrado em Administração Rural) Universidade Federal de Lavras: Lavras-MG, 2000.

OLIVEIRA, R. E. S.; SILVA, M. J. Da; COUTINHO, E. P.; MOREIRA, R. T.; CRUZ, G. R. B. Da. Perfil e hábitos dos consumidores de cachaça no Estado da Paraíba. Semina: Ciências Agrárias, Londrina-PR, v. 33, n. 1, p. 259-270, 2012. DOI: http://dx.doi.org/10.5433/16790359.2012v33n1p259.

PAIVA, A. L.; SOUZA, R. B.; BARRETO, I. D. C. De; BRITO, M. J. De. Fluxo das exportações brasileiras de cachaça: traços da influência do Estado no setor. Revista de Economia e Sociologia Rural, Brasília, v. 55, n. 4, p. 733-750, 2017. DOI: https://doi.org/10.1590/123456781806-94790550407. 
Consumo de cachaça e seus sentidos:

uma análise do comportamento do consumidor à luz da teoria do Sensemaking

PINTO, M. R. de; BATINGA, G. L. O consumo consciente no contexto do consumismo moderno: algumas reflexões. Revista Gestão Org., Recife, v. 14, Edição Especial, p. 30-43, 2016. DOI: http://dx.doi.org/10.21714/1679-18272016v14Esp.p30-43.

PINTO, M. R.; LARA, J. E. As experiências de consumo na perspectiva da teoria da cultura do consumo: identificando possíveis interlocuções e propondo uma agenda de pesquisa.

Cadernos EBAPE-BR, Rio de Janeiro, v. 9, n. 1, p. 37-56, 2011. DOI:

https://doi.org/10.1590/S1679-39512011000100004.

QUINTÃO, R.T.; BRITO, E.P.Z.; BELK, R.W. The taste transformation ritual in the specialty coffee market. Revista de Administração de Empresas, São Paulo, v. 57, n. 5, p. 483-494, 2017. DOI: https://doi.org/10.1590/s0034-759020170506.

RETONDAR, A. M. A (re)construção do indivíduo: a sociedade de consumo como "contexto social" de produção de subjetividades. Sociedade e Estado, Brasília, v. 23, n. 1, p. 137-160, 2008. DOI: https://doi.org/10.1590/S0102-69922008000100006.

ROCHA, E.; BARROS, C. Dimensões culturais do marketing: teoria antropológica, etnografia e comportamento do consumidor. RAE, São Paulo, v. 46, n. 4, p. 36-47, 2006.

SANDRE, S. Cachaça: patrimônio brasileiro. 2004. Monografia (Pós- Graduação em Gastronomia e Segurança Alimentar) - Universidade de Brasília, Brasília: 2004.

SILVA, F. R. da. Na embriaguês da cachaça: produção, imaginário e marketing. 2009. Dissertação (Mestrado em História) - Universidade Federal de Uberlândia: Uberlândia-MG, 2009.

TAVARES, A. G.; DANTAS, J. P.; NÓBREGA, W. R. M. A cachaça como patrimônio cultural e turístico. Revista Hospitalidade. São Paulo, v. 12, n. 1, p. 387-410, 2015.

TEIXEIRA, D. J.; SHIGAKI, H. B. Os estudos de consumo em uma perspectiva cultural e simbólica sob a ótica da teoria de Marketing. In: PINTO, M. de R.; BATINGA, G. L. (Org.). Cultura e consumo no Brasil: estado atual e novas perspectivas. Belo Horizonte: PUC-Minas, 2018, p. 59-82.

TEIXEIRA, J. C.; NASCIMENTO, M. C. R.; ANTONIALLI, L. M. Perfil de estudos em administração que utilizaram triangulação metodológica: uma análise dos anais do ENANPAD de 2007 a 2011. Revista Adm., São Paulo, v. 48, n.4, p. 800-812, 2013. https://doi.org/10.5700/rausp1122.

TONI, D. de; LARENTIS, F.; MATTA, A. Consumo consciente, valor e lealdade em produtos ecologicamente corretos. Revista Adm. FACES Journal, Belo Horizonte, v. 11, n.3, p. 136156, 2012.

WEICK, K. E. Sensemaking in organizations. Thousand Oaks: Sage Publications, 1995. 
Elisabeth Thaiane Tercino de Araújo, José Kennedy Lopes Silva, Flávia Carolini Pereira dos Santos e Ana Cristina Ferreira

WEICK, K. E.; SUTCLIFFE, K. M.; OBSTFELD, D. Organizing and the Process of Sensemaking. Organization Science, v. 16, n. 4, p. 409-421. 2005.

WEICK, K. E. Organized sensemaking: A commentary on processes of interpretive work.

Human Relations, v. 65, n. 1, p. 141-153, 2012. DOI:

https://doi.org/10.1177/0018726711424235.

ZANELLA, E. D. Masculinidade e consumo de bebidas alcoólicas: a construção de maneiras de beber. Ponto Urbe, São Paulo, v. 9, p. 1-8, 2011. DOI:

https://doi.org/10.4000/pontourbe.1820. 